\title{
Reestruturação Curricular a partir da Educação do/no \\ Campo e atividades de Clube de Ciências
}

\section{Curricular Restructuring from Field Education and Science Club Activities}

\author{
Andressa Luana Moreira Rodrigues (andressaluana.mr@hotmail.com) \\ Universidade Federal do Rio Grande do Sul (UFRGS) \\ José Vicente Lima Robaina (joserobaina326@gmail.com) \\ Universidade Federal do Rio Grande do Sul (UFRGS)
}

\begin{abstract}
Resumo: Este artigo objetiva pesquisar sobre Reestruturação do Currículo por intermédio das práticas pedagógicas realizadas no Clube de Ciências em uma Escola do/no Campo. Foi feito um levantamento por autores da área, das publicações realizadas entre os anos de 2013 até 2019 que contemplam Educação do Campo, Reestruturação Curricular, Territorialidade e Clube de Ciências, a fim de compreender e identificar o que vem sendo pesquisado sobre esses temas. É uma pesquisa quanti-qualitativa de caráter bibliográfico, com a proposta de fazer mapeamento da produção científica. As buscas foram realizadas nas seguintes fontes de informações, Revista Brasileira de Educação do Campo (RBEC) a partir 2016, nos anais do ENPEC de 2013 a 2017 e na Base Digital de Teses e Dissertações (BDTD) de 2015 a 2019. Os trabalhos foram selecionados primeiramente pelo título, como segundo filtro foi feita a leitura dos resumos e na sequência a leitura completa dos trabalhos que tinham mais relevância à pesquisa. Entre os trabalhos selecionados obteve-se dois (2) títulos na RBEC, um (1) título nas dissertações e um (1) nas teses da BDTD, nos ENPEC IX, X e XI, respectivamente, duas (2), quatro (4) e cinco (5) atas. Para análise de resultados foram observadas as instituições onde foram desenvolvidas as suas pesquisas, sujeitos da pesquisa, nível escolar, foco temático, títulos e autores separados de acordo com o seu foco temático (tema proposto). Os resultados destacam uma importante relevância entre as temáticas abordadas, assim como, análise sobre os autores citados, as instituições onde foram realizadas as pesquisas, temáticas abordadas e o público-alvo estudado.
\end{abstract}

Palavras-Chave: Educação do/no Campo; Clube de Ciências; Reestruturação Curricular; Territorialidade.

\begin{abstract}
This article aims to research Curriculum Restructuring through the pedagogical practices carried out at the Science Club in a School in the countryside. A survey was carried out by authors in the area, of the publications made between the years 2013 to 2019 that contemplate Field Education, Curricular Restructuring, Territoriality and Science Club, in order to understand and identify what has been researched on these themes. It is a quantitative and qualitative research of bibliographic character, with the proposal to map scientific production. The searches were carried out in the following sources of information, Revista Brasileira de Educação do Campo (RBEC) from 2016, in the annals of ENPEC from 2013 to 2017 and in the Digital Base
\end{abstract}


of Theses and Dissertations (BDTD) from 2015 to 2019. The papers were firstly selected by the title, as the second filter the abstracts were read and then the full reading of the works that were most relevant to the research. Among the selected works, two (2) titles were obtained in RBEC, one (1) title in dissertations and one (1) in BDTD theses, in ENPEC IX, X and XI, respectively, two (2), four (4) and five (5) minutes. For the analysis of results, the institutions where their research was conducted, research subjects, school level, thematic focus, titles and authors separated according to their thematic focus (proposed theme) were observed. The results highlight an important relevance among the themes addressed, as well as an analysis of the authors mentioned, the institutions where the research was carried out, the themes addressed and the target audience studied.

Keywords: Education of/in the Field. Science Club. Curricular Restructuring.

\section{INTRODUÇÃ̃O}

Esse estudo tem a proposta de pesquisar sobre Reestruturação do Currículo através das práticas pedagógicas realizadas no Clube de Ciências em uma Escola do/no Campo. Buscou-se compreender e verificar o que vem sendo pesquisado sobre os temas citados acima e averiguar quais as abrangências desses Unitermos dentro do cenário da Educação do/no Campo, bem como, os autores de referência dessas temáticas.

No artigo são apresentados resultados parciais de uma pesquisa mais ampla, que faz parte da escrita da dissertação desenvolvida em curso de Pós-Graduação stritco sensu, em Universidade pública do Sul do Brasil.

Segundo a definição de Costa (1988, p. 38) um Clube de Ciências é um local "onde todos os interessados pudessem trocar ideias reuniões, leituras e, acima de tudo, pesquisas dentro da própria comunidade". Se trata de um espaço de construção do conhecimento, acima de tudo os educandos aprendem conceitos científicos é um momento de reflexão e troca de saberes entre os pares. Os Clubes de Ciências são espaços que contribuem para o senso crítico dos alunos, assim como, seu processo formativo. Gomes (1998) explica:

\footnotetext{
Clube de Ciências é uma atividade em que o processo ensino-aprendizagem se desenvolve paralelamente a um importante processo formativo e educativo; e que ambos se desenrolam de modo espontâneo e pleno de afetividade, com resultados verdadeiramente magníficos. (GOMES, 1998, p. 40)
}

Os Clubes de Ciências devem utilizar uma linguagem que melhore a nossa compreensão sobre o mundo (CHASSOT, 2006). As atividades realizadas devem ser estimulantes e lúdicas sobre 
temas diversos, as quais terão sempre uma correlação com o mundo real, o que é muito importante para a Educação no Campo.

Foi através da $1^{\text {a }}$ Conferência Nacional por uma Educação Básica no campo realizada em 1998, que houve o início de uma nova forma de pensar e batalhar a educação para os cidadãos brasileiros que trabalham e vivem no e do campo. Por intermédio desta conferência surgiram novos parâmetros, isto é, agora Educação no Campo e não mais Educação Rural (CALDART, 2002 APUD MOLINA E JESUS, 2004). "Na 1 a Conferência reafirmamos que o campo é espaço de vida digna e que é legítima a luta por políticas públicas específicas e por um projeto educativo próprio para seus sujeitos" (CALDART APUD MOLINA \& JESUS, 2004, p. 14).

Na concepção de Arroyo (1998) em relação a Educação do Campo estamos tratando da educação voltada ao conjunto dos trabalhadores e trabalhadoras do campo, podendo ser indígenas ou os diversos tipos de assalariados vinculados à vida e ao trabalho no meio rural, ou seja, no campo. A Educação Básica do campo tem como propósito o desenvolvimento sociocultural e econômico dos povos que habitam e trabalham no campo.

Conforme Rosa e Robaina (2020) a Educação do Campo é a forma de ensino que deve acontecer em lugares denominados rurais nos municípios. Tem relação com os espaços educativos que estão fora da área urbana, tais como: regiões agrícolas com predomínio da agricultura e da agropecuária, populações ribeirinhas, assentamentos indígenas, florestas, comunidades quilombolas, entre outras.

O reconhecimento de que as pessoas que vivem no campo têm direito a uma educação diferente daquela oferecida para quem vive nas cidades é recente. Ele extrapola a noção de espaço geográfico e compreende as necessidades culturais, os direitos sociais e a formação integral desses indivíduos, tornando-se uma proposta inovadora no universo educacional. (ROSA E ROBAINA, 2020, p. 157).

De acordo com Arroyo (2013 apud Molina e Jesus, 2004, p. 91) "O tratamento da Educação do Campo está mudando. É reconhecida sua especificidade. Sobretudo se avança no reconhecimento de que urge outro tratamento público do direito dos povos do campo à educação". Os autores Fernandes e Molina (2002 apud Molina e Jesus, 2004, p. 23) concordam com essa ideia dizendo que "o campo não comporta hoje a compreensão unidimensional do rural", dessa forma, compreende-se que hoje o modelo de educação que apoia-se na visão tradicional do meio rural no Brasil não fará as inter-relações emergentes da sociedade, nem irá incorporar as necessidades trazidas à sociedade através dos movimentos sociais.

Nesse contexto, é fundamental a compreensão do significado DO/NO campo conforme Caldart (2002) o DO: pensado naquele lugar nos sujeitos e na cultura e necessidades daquele povo em questão; NO: os sujeitos têm direito de receber educação no lugar onde vive. 
É desse modo que a Educação do/no Campo vem rompendo paradigmas, pois está em busca da própria identidade de uma Educação do/no Campo, através da Construção de um Projeto Político Pedagógico construído e pensado nos sujeitos e pelos sujeitos desse território.

A proposta de Educação do Campo existe desde sua criação e normativa. Movimentos de Educação do Campo Resolução CNE/CEB n ${ }^{\circ}$ 1/2002 e resolução CNE/CEB n 2/2008, estipulando as Diretrizes Operacionais para Educação Básica das escolas de campo e o Decreto $\mathrm{n}^{\mathrm{o}} 7.352$, de 4 de novembro de 2010, que dispõe sobre a Política Nacional de Educação do Campo e sobre o Programa Nacional de Educação na Reforma Agrária (PRONERA). Segundo decreto n ${ }^{\circ}$ 7.352/10:

Art. $1^{\circ}$ - A política de Educação do Campo destina-se à ampliação e qualificação da oferta de Educação Básica e superior às populações do

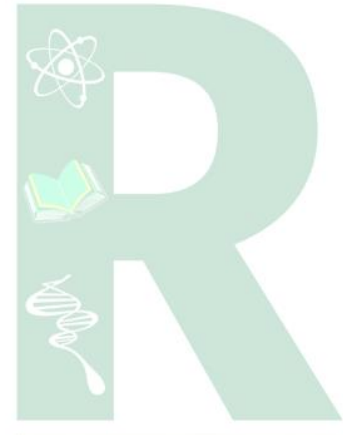
campo, e será desenvolvida pela União em regime de colaboração com os Estados, o Distrito Federal e os Municípios, de acordo com as diretrizes e metas estabelecidas no Plano Nacional de Educação e o disposto neste Decreto. § 1o Para os efeitos deste Decreto, entende-se por:

I - populações do campo: os agricultores familiares, os extrativistas, os pescadores artesanais, os ribeirinhos, os assentados e acampados da reforma agrária, os trabalhadores assalariados rurais, os quilombolas, os caiçaras, os povos da floresta, os caboclos e outros que produzam suas condições materiais de existência a partir do trabalho no meio rural;

II - escola do campo: aquela situada em área rural, conforme definida pela Fundação Instituto Brasileiro de Geografia e Estatística - IBGE, ou aquela situada em área urbana, desde que atenda predominantemente a populações do campo. (DECRETO No 7.352, 2010, p. 1).

Ainda refletindo sobre a importância de uma identidade, não podemos esquecer que a do Sem Terra - MST que tem origem na cultura camponesa e nas questões do campo, sua construção perpassa pela ideia de sujeitos sociais organizados de forma coletiva pela conquista/luta pela terra e pelos seus direitos e por uma educação emancipatória para seus filhos.

Para compreender a Educação do Campo o educador precisa conhecer e entender o território, o qual é considerado por Fernandes e Molina (2002 apud Molina e Jesus, 2004) como algo a mais, é uma vantagem, dos cidadãos do campo. Viver e trabalhar na terra, tirar dela seu sustento requer conhecimentos que são embasados nas experiências cotidianas e na escola. Ter seu território importa em uma maneira de pensar a realidade.

Para garantir a identidade territorial, a autonomia e a organização política, é preciso pensar a realidade desde seu território, de sua comunidade, de seu município, de seu país, do mundo. Não se pensa o próprio território a partir do território do outro. [...]. Os povos do campo e da floresta têm como base de sua existência o território, onde reproduzem as

Recebido em: $13 / 04 / 2020$

Aceito em: $23 / 12 / 2020$ 
relações sociais que caracterizam suas identidades e que possibilitam a permanência na terra. [...] Esses grupos sociais, para fortalecerem, necessitam de projetos políticos próprios de desenvolvimento socioeconômico, cultural e ambiental. E a educação é parte essencial desse processo. (FERNANDES \& MOLINA, 2002 APUD MOLINA \& JESUS, 2004, p. 60-61).

O território, este que não está apenas distante da cidade, mas sim que é um campo de conhecimento riquíssimo, campo de produção de conhecimento, de lutas e de muita vida. Não se trata apenas de território, de plantações, distâncias e gente simples trabalhadora: são vivências que devem ser ouvidas, de pessoas e famílias que precisam ser conhecidas, de trabalho que precisa ser reconhecido, um campo que constantemente gera vida e luta por ela.

De acordo com Arroyo (2013), em seu livro intitulado "Currículo, território em disputa", o autor enfatiza que os sujeitos sociais e suas vivências se consolidam no espaço do conhecimento, ou seja, os grupos sociais revelam que os saberes têm seu limiar na experiência social e não somente no artificialismo das teorias epistemológicas. Esse fato não deve ser ignorado ou negado, pois se isso acontecer se isso for além de injustiça social, produziremos uma injustiça cognitiva.

Para Arroyo (2013), separar experiências sociais e conhecimentos legítimos é apoiar a intransigente hierarquia dos saberes, é jogar fora essas experiências sociais desconsiderando sua importância, assim os currículos são empobrecidos pelo desprezo das experiências sociais e da sua diversidade. Para este autor, a arte de ensinar não pode ser separada do mundo real dos sujeitos, de seus problemas e de seus anseios. Segundo Fiori (2014) "A prática da Liberdade só encontrará adequada expressão numa pedagogia em que o oprimido tenha condição de, reflexivamente, descobrir-se e conquistar-se como sujeito de sua própria destinação histórica" (FIORI APUD FREIRE, 2014, p. 11).

Quando o currículo contempla a realidade de seus educandos, está dando a este a condição de perceber-se como sujeito da própria história e sentir-se inserido e pertencente ao mundo. Os Clubes de Ciências são espaços de ensino-aprendizagem, de acordo com Gomes (1988 apud Mancuso et al, 1996, p. 23), "Clube de Ciências é uma atividade em que o processo ensino aprendizagem se desenvolve paralelamente [...]", que permite a aprendizagem não somente no aspecto cognitivo, mas nas relações sociais e permite fazer inferências. O Ensino de Ciências nas escolas ainda ocorre como "Educação Bancária“, assim denominada por Freire (2014), onde o professor é o detentor do saber. Essa forma de ensinar acaba tornando a ciência em algo distante da realidade dos educandos, sendo que a Ciência está presente nas coisas mais corriqueiras do cotidiano. 


\section{METODOLOGIA}

O método de pesquisa utilizado neste artigo é quali-quantitativo, segundo Flick (2004) salienta a credibilidade e legitimidade aos resultados encontrados na pesquisa. $\mathrm{O}$ artigo trata-se de um estudo que se caracteriza como descritivo e exploratório fazendo um levantamento bibliográfico, referente aos Unitermos: Educação do Campo, Currículo, Clube de Ciências e Território.

A Biblioteca Digital de Teses e Dissertações (BDTD) é um banco eletrônico de teses e dissertações que disponibiliza os trabalhos completos da produção acadêmica da Pós-Graduação stricto sensu das Instituições de Educação Superior do Brasil. Para a investigação das teses e dissertações foi pesquisado os Unitermos: Educação do/no Campo, Clube de Ciências, Currículo e Diversidade Territorial, no espaço de tempo de 2015 até 2019 através do mecanismo de busca avançada no portal eletrônico da BDTD. Colocando os Unitermos um a um entre aspas na barra de busca e selecionando o período de tempo entre 2015 até 2019 e selecionando entre teses e dissertações.

O Encontro Nacional de Pesquisadores em Educação de Ciências (ENPEC) é um evento, bianual, com grande representação no campo da pesquisa, promovido pela Associação Brasileira de Pesquisa em Educação em Ciências (ABRAPEC). Os artigos do evento ENPEC (edições IX, X e XI) foram encontrados on-line, mediante a pesquisa por "temas" e "palavras chaves", selecionando-se cada um dos quatro Unitermos mencionados anteriormente.

Outra fonte de pesquisa foi a Revista Brasileira de Educação do Campo (RBEC), que tem como abordagem em suas publicações as temáticas sobre Educação do Campo e Movimentos Sociais com abrangência Internacional. A procura pelos Unitermos ocorreu através do mecanismo de busca, proporcionada pelo sistema da RBEC, foram selecionados os Unitermos: Educação do/no Campo, Clube de Ciências, Currículo e Diversidade Territorial, no espaço de tempo de 2016 a 2018.

O mesmo processo de filtragem foi utilizado para as três diferentes fontes de informações utilizadas para elaboração dessa pesquisa. Iniciou-se com a leitura dos títulos, após a seleção dos títulos ocorreu a leitura dos resumos e por último a leitura criteriosa e completa dos trabalhos selecionados.

\section{RESULTADO E DISCUSSÕES}

Como mencionado anteriormente, este trabalho teve o intuito de pesquisar sobre a Reestruturação do Currículo através das práticas pedagógicas realizadas no C.C em uma Escola do/no Campo. A pesquisa buscou analisar e investigar os artigos publicados no ENPEC, das 
edições que ocorreram entre os anos de 2013, 2015 e 2017, totalizou três encontros. No primeiro, o IX ENPEC, foi possível encontrar um total de trinta e dois (32) trabalhos, no X ENPEC foram encontrados cinquenta e um (51) artigos e no XI ENPEC um total de sessenta (60) artigos, como mostra a Tabela 1.

Tabela 1 - Dados dos trabalhos selecionados a partir dos Unitermos IX ENPEC, X ENPEC e XI ENPEC.

\begin{tabular}{|c|c|c|c|c|c|c|c|c|c|c|c|c|}
\hline \multirow{2}{*}{ Unitermos } & \multicolumn{4}{|c|}{$\begin{array}{c}\text { IX ENPEC } \\
2013\end{array}$} & \multicolumn{4}{|c|}{$\begin{array}{c}\text { X ENPEC } \\
2015\end{array}$} & \multicolumn{4}{|c|}{$\begin{array}{c}\text { XI ENPEC } \\
2017\end{array}$} \\
\hline & $\begin{array}{l}\text { Tít. } \\
\text { Enc. }\end{array}$ & Título & Resumo & Artigo & $\begin{array}{l}\text { Tít. } \\
\text { Enc. }\end{array}$ & Título & Resumo & Artigo & $\begin{array}{l}\text { Tít. } \\
\text { Enc. }\end{array}$ & Título & Resumo & Artigo \\
\hline Currículo & 29 & 3 & 2 & 1 & 45 & 4 & 2 & 1 & 47 & 12 & 5 & 2 \\
\hline $\begin{array}{ll}\text { Clube de } \\
\text { Ciências }\end{array}$ & 1 & 1 & 1 & O & 3 & 2 & 2 & 2 & 5 & 5 & 4 & 1 \\
\hline $\begin{array}{l}\text { Educação do } \\
\text { Campo }\end{array}$ & 2 & 2 & 1 & 1 & 3 & 2 & 1 & 1 & 8 & 6 & 4 & 2 \\
\hline $\begin{array}{l}\text { Diversidade } \\
\text { Territorial }\end{array}$ & O & o & o & o & 0 & 0 & O & 0 & 0 & O & O & o \\
\hline Total & 32 & 6 & 4 & 2 & 51 & 8 & 5 & 4 & 60 & 23 & 13 & 5 \\
\hline
\end{tabular}

Fonte: Elaborada pela própria autora (2019).

Observando a Tabela 1 é possível perceber o crescimento das temáticas abordadas nessa pesquisa durante os três eventos do ENPEC. Podendo destacar que as pesquisas no Currículo de Ciências têm crescido nos últimos três eventos, somente do ano de 2013 para o ano de 2015 ocorreu um aumento de dezesseis artigos publicados, já do ano de 2015 para o ano 2017 aumentaram dois. Isso demonstra que o número de pesquisas vem aumentando uma vez que há uma preocupação em reelaborar o Currículo em Ciências.

A temática Clube de Ciências (C.C) mostrou um aumento significativo nos últimos três anos, essa alta foi de dois artigos por evento. No ano de 2013 quando foi publicado apenas um trabalho, no ano de 2015 foram publicados três artigos e no ano de 2017 foram publicados cinco artigos relacionados com Clube de Ciências. De acordo com esses dados apresentados, podemos atrelar ao fato de criações de Clubes de Ciências nas escolas, tanto no Ensino Fundamental II do $6^{\circ}$ ao $9^{\circ}$ ano, como no Ensino Médio, a partir disto verificou-se que não foi encontrado nenhum artigo relacionado Clubes de Ciências nas séries iniciais do Ensino Fundamental.

A temática Educação do Campo vem crescendo dentro do ENPEC, somente do ano de 2013 para 2017 de dois (2) artigos passou para oito (8) artigos publicados. Entende-se, que tal crescimento dessa temática ocorreu após implementação nas universidades públicas dos cursos de Licenciatura em Educação do Campo - LEDOC em 2013. Essa modalidade de ensino vem buscando se consolidar como área de produção de conhecimento, porém a construção dessa 
política pública só aconteceu após muitos diálogos e pautas durante a segunda Conferência da Educação do Campo, como destaca MOLINA (2015, p. 150) “[...] prioridades requeridas pelo Movimento, ao término da II Conferência Nacional por uma Educação do Campo, realizada em 2004, cujo lema era exatamente "Por um Sistema Público de Educação do Campo", a partir desse lema foi sendo construída uma política nessa área da Educação Popular.

Em relação a temática Diversidade Territorial não foi encontrado nenhum artigo nas palavras-chave dos trabalhos. Mas, foi possível perceber que nos artigos relacionados a Currículo de Ciências e Educação do Campo esse Unitermo é bem presente dentro do corpo dessas pesquisas. O Quadro A Tabela 2 demonstra os trabalhos selecionados nas atas do ENPEC das edições IX, X e XI.

Tabela 2 - Planilha de classificação dos artigos publicados no ENPEC.
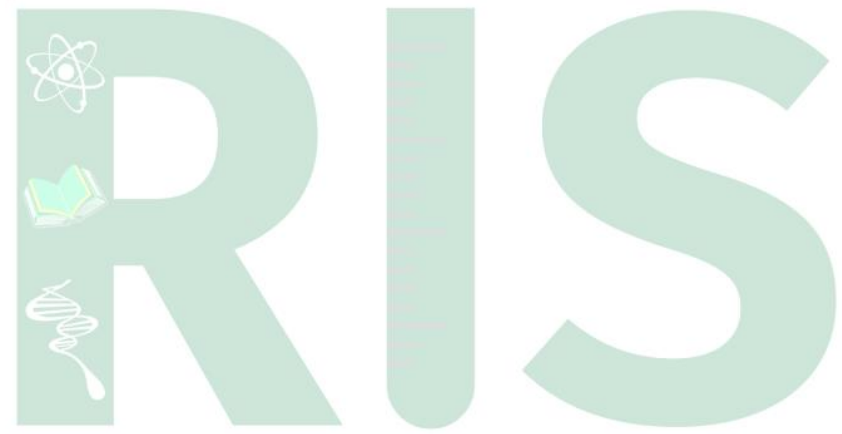

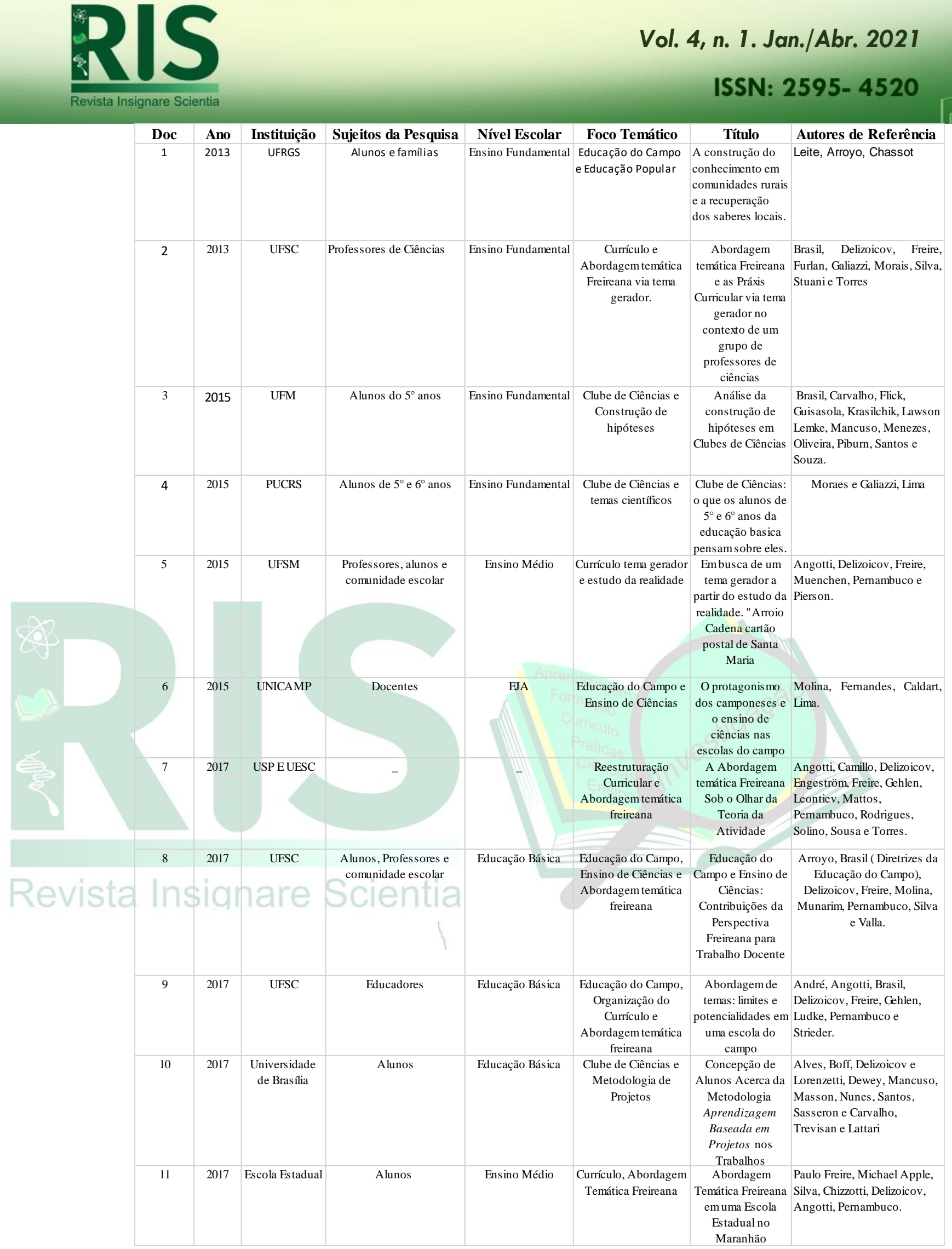

Fonte: Elaborada pela própria autora (2019).

Dos onze artigos selecionados do ENPEC, das edições que ocorreram entre 2013, 2015 e 2017, apenas um artigo não mostra ser de universidade e sim de uma Escola Estadual, um de universidade particular e oito de universidades públicas. Através desses dados é possível 
perceber a produtividade do trabalho de pesquisa dentro das universidades públicas que é maior que o das universidades privadas, esses dados podem ser observados na Tabela 2, na coluna Instituições. Percebe-se que as universidades públicas têm fomentado a prática da pesquisa e produção de artigos com seus alunos. Outro ponto importante que destaca-se é o fato dos professores somente produzirem artigos sobre suas práticas de ensino quando estão dentro da academia. Aproveito essa observação para relatar a importância das Universidades Públicas estarem diretamente ligada com as Escolas Públicas e na formação dos professores da rede pública.

Os sujeitos que mais participaram e foram objeto da pesquisa são os estudantes (educandos), depois professores (educadores), e por último, família ou comunidade escolar. Conforme a Tabela 2 pode-se observar que os documentos 5 e 8 mostraram três sujeitos tais como: estudantes, professores e comunidade escolar juntos na mesma pesquisa.

$\mathrm{Na}$ Tabela 2, é possível observar o nível de escolaridade onde foram realizadas as pesquisas mostradas nos artigos do IX ENPEC, X ENPEC e XI ENPEC. Dos onze (11) artigos selecionados oito (8) foram desenvolvidos no Ensino Fundamental ou Educação Básica, um (1) realizado no EJA e dois (2) no Ensino Médio, apenas um artigo não descreveu como âmbito escolar.

A análise dos artigos com a temática Currículo, usando a Tabela 2 para confrontar os dados. Os documentos 2, 5, 7, 9 e 11 têm em comum a reestruturação curricular a partir do aporte teórico de Paulo Freire. A construção do Currículo é elaborada através das falas significativas encontrada nas vozes da comunidade, essa proposta possibilita a percepção de visão de mundo dessas famílias, com base nas falas é encontrado o Tema Gerador.

A Abordagem Temática Freireana (ATF) elenca o diálogo e a problematização de situações significativas da realidade dos educandos. Outra observação pertinente é que dos cinco (5) artigos que trazem o tema Currículo é elencado com ATF, e a organização do Currículo em Ciências.

A temática Clube de Ciências está relacionada com metodologias de projetos, temas científicos e construção de hipóteses. Percebe-se que cada C.C tem uma maneira específica de trabalhar, sempre voltado para prática de experiências dentro de laboratórios. Mas afinal, como surgiram os clubes de ciências no Brasil? Os Clubes de Ciências surgiram no final da década de 50, assim como o novo modelo de Currículo de Ciências que estava moldado para preparar seus educandos para ser "pequenos cientistas", através de atividades experimentais nos laboratórios, as chamadas "metodologias científicas". Dessa forma, pode-se observar que alguns C.C ainda seguem na mesma dinâmica, em atividades experimentais desenvolvidas em laboratórios. 
A palavra Ciências ficou em destaque, pois todos os artigos fazem menção ao Ensino de Ciências, assim como, o Currículo em Ciências, por se tratar de um Encontro Nacional de Pesquisa em Educação em Ciências, ou seja, todos os títulos selecionados tratam da temática Ciências em suas pesquisas.

A partir dos artigos selecionados após uma leitura criteriosa tanto dos resumos como dos trabalhos completos, foram destacados fatos e referências relacionando com essa pesquisa do estado da arte que serão utilizadas no futuro como aporte teórico da dissertação. A Tabela 3 separa os autores de acordo com o foco temático abordado nos trabalhos selecionados do ENPEC das edições IX, X e X.

Tabela 3 - Autores de acordo com o foco temático abordado nos trabalhos selecionados.

\begin{tabular}{c|c|c}
\hline Ed. do/no Campo & $\begin{array}{c}\text { Ed. Ciências e Clube de } \\
\text { Ciências }\end{array}$ & Currículo \\
\hline Arroyo & Chassot & Arroyo \\
\hline Freire & Mancuso & Freire \\
\hline Caldart & Lawson & Ludke \\
\hline Brasil & Angotti & Boff \\
\hline Molina & Delizoicov & Torres \\
\hline Silva & Engeström & Muenchen \\
\hline Munarim & Gehlen & Delizoicov \\
\hline Valla & Brasil & Silva \\
\hline Fernandes & Carvalho & Pernambuco \\
\hline & Santos & Apple \\
\hline IStarlan \\
\hline HSIONal & Guisasola & Stuani \\
\hline & Krasilchik & \\
\hline & Menezes & \\
\hline & Oliveira & \\
\hline & Souza & \\
\hline & Lima & \\
\hline & Chizzotti & \\
\hline & Torres & \\
\hline
\end{tabular}

Fonte: Elaborada pela própria autora (2019).

A RBEC tem publicações contínuas online. A revista RBEC tem Qualis B1 no Ensino pela CAPES, os temas das publicações são sobre Educação do Campo e Movimentos Sociais e tem abrangência Internacional.

A busca pelos Unitermos ocorreu através do mecanismo de busca, proporcionada pelo sistema da RBEC, foram selecionados os Unitermos: Educação do no Campo, Clube de Ciências, Currículo e Diversidade Territorial. No período de 2016 a 2018 foram encontrados um total de cento e sessenta e seis (166) trabalhos, contando com o cruzamento dos Unitermos. 
Com as diferentes combinações para o cruzamento dos Unitermos, muitos artigos se repetiam. Com os trabalhos já selecionados foi realizado o processo de filtragem, primeiro se deu pela escolha do título do trabalho, depois leitura do resumo e leitura do artigo. Como mostra a Tabela 4.

Tabela 4 - Dados dos trabalhos selecionados a partir dos Unitermos, RBEC.

\begin{tabular}{lcccc}
\hline Unitermos & Trabalhos encontrados & Título & Resumo & Artigo \\
\hline Currículo & 18 & 2 & 1 & 1 \\
\hline Clube de Ciências & 0 & 0 & 0 & 0 \\
\hline Educação do Campo & 147 & 10 & 4 & 1 \\
\hline Diversidade Territorial & 1 & 1 & 1 & 4 \\
\hline TOTAL & 166 & 13 & 6 & 4 \\
\hline
\end{tabular}

Fonte: Elaborada pela própria autora (2019).

Com as análises do Unitermo Currículo a partir do ano de 2016 até 2019 foram encontrados dezoito trabalhos. A partir do processo de filtragem que se deu pela escolha do título e assim foram selecionados apenas dois trabalhos, o próximo processo de filtragem ocorreu através da leitura do resumo, onde restou apenas um para realizar a leitura do artigo.

Com o Unitermo Clube de Ciências não foi encontrado nenhum artigo durante o período de 2016 até 2019, esse fato reforça a importância dessa temática ser considerada como "atual" e nova. Destaco esse tema como atual porque somente no Município de Nova Santa Rita/RS, existe cinco Clubes de Ciências contemplando as séries iniciais e a Educação do Campo. A partir do Programa de Extensão que trata da Formação de Professore do Campo o Projeto Clube de Ciências do Campo da Faculdade de Educação da Universidade Federal do RS FACED/UFRGS, criado e coordenado pelo Professor Dr. José Vicente Lima Robaiana idealizador deste projeto que tem como objetivo:

O clube de ciências do campo é um Projeto de formação de professores e educadores EDUCAMPO/ FACED/UFRGS, que tem como o objetivo estimular, por meio atividades interdisciplinares e culturais, e incitar o desenvolvimento do caráter crítico e cientifico, estimular o anseio dos jovens pela cidadania, meio ambiente, ciências e tecnologia e participar de atividades lúdicas que envolvam conteúdos relacionados a ciências. Este projeto faz parte do programa de formação de professores que está sendo desenvolvido em escolas do campo com objetivo de fomentar a ciência através da produção de conhecimentos oriundos das vivencias cotidianas dos educandos destas escolas. (CLUBE DE CIÊNCIAS DO CAMPO, 2020, p. $1)$. 
Foi através desse Projeto de formação de professores e educadores EDUCAMPO/FACED/UFRGS ministrado pelo professor coordenador para os docentes das Escolas do Campo da cidade de Nova Santa Rita/RS, que se iniciou a construção dos C.C do Campo nas séries iniciais. Com base nessa formação cada uma das cinco Escolas do Campo desse município criaram o seu C.C do Campo de acordo com a sua realidade escolar. Com isso podemos destacar que essa temática não é recente, mas segue sendo atual a partir dos dados apresentados anteriormente, pois os primeiros registros de C.C no Brasil surgiram no final da década de 1950 (MANCUSO, 1996).

A partir da temática Educação do Campo foram encontrados cento e quarenta e sete (147) trabalhos, esse valor se deve a característica da Revista, pois é uma Revista Brasileira de Educação no Campo onde o foco temático é esse tema. Com esse Unitermo foram encontrados mais artigos no período de 2016 até 2019. A partir da leitura dos artigos encontrados foram selecionados dez (10) artigos, ficando para leitura dos resumos quatro (4) artigos e para realizar o último filtro que seria a leitura do artigo completo, apenas dois ( 2) trabalhos foram selecionados.

Diversidade Territorial foi encontrado apenas um (1) artigo, durante o processo de busca no banco de dados da revista quando descrevia o Unitermo Diversidade Territorial os artigos se repetiam, ou seja, os mesmos artigos que apareciam para o Unitermo Educação do Campo se apareciam para Diversidade Territorial. Para encontrar esse Unitermo, foi selecionado a partir das "palavras-chave" encontradas no corpo dos resumos dos artigos. Apenas um artigo tinha esse Unitermo descrito nas "palavras-chave" de seu resumo. A Tabela 5 mostra os artigos selecionados para discussão.

Tabela 5 - Planilha de classificação dos artigos publicados no RBEC. 


\begin{tabular}{|c|c|c|c|c|c|}
\hline Doc & Ano & Instituição & Foco Temático & Títulos & Autores da Pesquisa \\
\hline 1 & 2017 & $\begin{array}{c}\text { UFPA } \\
\text { SEMEC }\end{array}$ & $\begin{array}{l}\text { Educação do Campo, } \\
\text { Movimentos Sociais e } \\
\text { Política Educacionais }\end{array}$ & $\begin{array}{c}\text { Educação do } \\
\text { Campo e Políticas } \\
\text { no Município de } \\
\text { Abaetetuba - Pará }\end{array}$ & $\begin{array}{c}\text { Leite, Bagno, Silva, Gomes, } \\
\text { Silva e Wanzeler, Arroyo, } \\
\text { Caldart e Molina, Molina e } \\
\text { Freitas, Canali, Oliveira, } \\
\text { Paulo Freire, Brito, Haje }\end{array}$ \\
\hline 2 & 2017 & UFMT & $\begin{array}{c}\text { Projeto Político } \\
\text { Pedagógico e } \\
\text { Educação do Campo }\end{array}$ & $\begin{array}{l}\text { O Significado do } \\
\text { Projeto Político } \\
\text { Pedagógico na } \\
\text { Construção de } \\
\text { Ações e Relações }\end{array}$ & $\begin{array}{c}\text { Brasil, Caldart, Carvalho, } \\
\text { Garske, Koling e Molina, } \\
\text { Machado }\end{array}$ \\
\hline 3 & 2018 & UFFS & $\begin{array}{c}\text { Educação do Campo, } \\
\text { Ensino e } \\
\text { Aprendizagens }\end{array}$ & $\begin{array}{l}\text { As Relações entre } \\
\text { Escola e } \\
\text { Comunidade na } \\
\text { Concepção de } \\
\text { Professores que } \\
\text { Atuam na } \\
\text { Educação do } \\
\text { Campo }\end{array}$ & $\begin{array}{c}\text { Arroy, Brasil, Caldart, } \\
\text { Costa e Cabral, Graupe e } \\
\text { Pereira, Fernandes, Parana, } \\
\text { Ribeiro, Silveira, Trindade }\end{array}$ \\
\hline 4 & 2019 & $\begin{array}{c}\text { UFMT } \\
\text { SEDUC/MT }\end{array}$ & Escola do Campo & $\begin{array}{l}\text { Organização da } \\
\text { Escola do Campo: } \\
\text { Concepções e } \\
\text { Expectativas de } \\
\text { Professores }\end{array}$ & $\begin{array}{l}\text { Arroy, Caldart, Carvalho e } \\
\text { Cunha, Libâneo, Garcia, } \\
\text { Ludke e André, Jesus, } \\
\text { Kolling, Nery e Molina, } \\
\text { Fernandes, Criolo e } \\
\text { Caldart, Severino }\end{array}$ \\
\hline
\end{tabular}

Fonte: Elaborada pela própria autora (2019).

Dos quatro artigos selecionados da RBEC, das edições que ocorreram em 2017, 2018 e 2019, são de Universidades Federais. Com a leitura dos artigos apresentados na Tabela 5 observa-se que ambos os Doc. 2 e 3 estão vinculados a Universidades Federais, assim como seus autores. Os Doc. 1 e 4 estabelece uma relação de trabalho científico entre secretarias e universidades. O Doc. 1 estabelece uma relação de parceria entre secretaria municipal e Universidade Federal, o Doc. 4 mostra uma interatividade entre a secretaria estadual com a Universidade Federal, porém durante a leitura detalhada desses artigos não ficou claro o vínculo entre essas instituições pública.

A análise dos artigos selecionados destaca a temática "Educação do Campo" como palavra-chave dos artigos, sendo que essa temática aparece junto com Projeto Político Pedagógico construído de forma democrática dentro da realidade das Escolas do Campo.

Outra temática abordada entre os trabalhos selecionados são os Movimentos Sociais e Políticas Educacionais, não tem como separar Educação do Campo desses dois termos, pois se hoje existe Políticas Educacionais para Educação do/no Campo é graças aos Movimentos Sociais que lutaram pelo direito a Educação.

O ensino e a aprendizagem das Escolas do/no Campo devem atender as necessidades dos seus sujeitos, fazendo os educandos encontrarem sentido entre o que se aprende na escola com as práticas sociais de seu cotidiano familiar, estabelecendo um diálogo entre a teoria e a prática. 
A Tabela 6 está separada com os Unitermos da pesquisa Clube de Ciências, Currículo, Educação do Campo e Diversidade Territorial. A partir deles foram separados os autores, que foram retirados dos artigos analisados da RBEC.

Tabela 6 - Autores conforme Unitermos.

\begin{tabular}{|ccc|}
\hline $\begin{array}{c}\text { Ed. do/no } \\
\text { Campo }\end{array}$ & Currículo & $\begin{array}{c}\text { Diversidade } \\
\text { Territorial }\end{array}$ \\
\hline Brasil & Carvalho & Fernandes \\
Arroyo & Cunha & Jesus \\
Caldart & Arroyo & Arroyo \\
Crioli & Caldart & \\
\hline
\end{tabular}

Fernandes

Jesus

Molina

Nery

Kolling

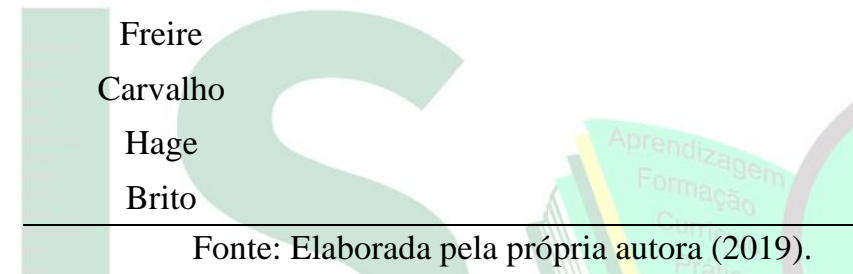

A BDTD compõe e dissemina em um portal eletrônico os trabalhos completos das dissertações e teses produzidas e defendidas nas Universidades Brasileiras de ensino e pesquisa.

Para Unitermo Educação do Campo foi encontrado cento e noventa e três (193) dissertações entre o período de 2015 até 2019, em um segundo momento foi realizado a leitura criteriosa dos títulos onde foram selecionados seis (6) dissertações para leitura dos resumos, após essa leitura restaram apenas uma dissertação para análise.

Os Unitermos Clube de Ciências e Diversidade Territorial não foram encontrados, nenhuma dissertação entre o período de 2015 até 2019.

O Unitermo Currículo foi encontrado cinquenta e dois (52) títulos de dissertações no período de 2015 até 2019, a partir da leitura dos títulos foram selecionados apenas uma dissertação para leitura do resumo, para o último filtro não restou nenhum trabalho selecionado.

\subsection{Dados da análise da dissertação}

O título da dissertação é "Percepções docentes sobre o Ensino de Ciências e a Educação do Campo em escolas do município de Toledo/PR" o estudo é de uma Universidade Estadual, 
cujo trabalho foi produzido por uma professora da rede estadual do Paraná, seu foco temático na dissertação Educação do Campo e o Ensino de Ciências, os sujeitos da pesquisa foram os professores da rede estadual de uma escola específica, o ano da pesquisa foi 2017. A autora Kliemann (2017), traz toda a normativa sobre a Educação do Campo no Brasil e no Estado do Paraná, assim como Ensino de Ciências nas Escolas do Campo.

Um dos temas abordados pela autora foi da escola ter a nomenclatura Educação do Campo, como parte do nome da instituição escolar assim como seu Projeto Político Pedagógico do campo. Segundo Kliemann (2017) “[...] foram a inserção da expressão do campo na nomenclatura da escola [...]", o trabalho traz as normativas da Educação do Campo e as percepções docentes sobre o Ensino de Ciências e a Educação do Campo em escolas do município de Toledo/PR.

Entre as dissertações pesquisadas não foi encontrada trabalhos com a seguinte temática C.C e os existentes seguem um padrão, todos realizados dentro de laboratórios e com alunos de sexto ano adiante e Ensino Médio, não foi encontrado nenhum trabalho nesse banco de dados sobre C.C no Currículo dos anos iniciais e nem nos anos finais.

Processo de filtragem das Teses para o Unitermo Educação do Campo foram encontrados quatro (4) teses no espaço de tempo de 2015 até 2019, após a leitura dos títulos foi selecionado duas (2) teses para segundo processo de filtragem da leitura do resumo onde não ficou nenhum trabalho para leitura completa da tese, pois os mesmos não respondiam aos Unitermos pesquisados.

O Uni termo Currículo foram encontrados quarenta e uma (41) teses entre 2015 e 2019, no primeiro filtro foi selecionado apenas um (1) título para leitura do resumo, após a leitura criteriosa não foi selecionado nenhum trabalho.

A respeito do Unitermo Clube de Ciências não foi encontrado nenhuma tese e o Unitermo Diversidade Territorial foi encontrado uma tese, mas o conteúdo do trabalho não fazia correspondência com o tema de fato.

\section{CONSIDERAÇÕES FINAIS}

Pela observação dos aspectos analisados neste artigo, relacionados aos Unitermos Educação do Campo, Clube de Ciências e Reestruturação Curricular, pode-se destacar como importantes considerações: a) A partir da territorialidade esses Unitermos têm mostrado presente entre as pesquisas junto aos demais Unitermos, porém não se encontrou essa temática nas palavras chaves dos artigos pesquisados; b) A Educação do/no Campo tem-se destacado no campo científico, assim, como, a Reestruturação Curricular a partir do território, com o aporte teórico 
de Paulo Freire; c) O C.C ainda tem muito para ser pesquisado, explorado e aproveitado pelas Escolas, principalmente no Currículo do fundamental I.

Entre os onze artigos selecionados nas edições IX, X e XI do ENPEC e os quatro trabalhos da REBEC e uma dissertação da BDTD, totalizando dezesseis trabalhos selecionados entre as três fontes de informações pesquisadas para este Estado da Arte, sendo que os mesmos trazem contribuições importantes no campo científico para os Unitermos selecionados, os mesmos fazem relação direta com as temáticas da futura dissertação do mestrado da autora a qual esta pesquisa é parte integrante.

Mediante as pesquisas realizadas nos anais dos eventos da RBEC, nos ENPEC's e na BDTD, foi possível perceber que os C.C têm poucos artigos, teses e dissertações sobre essa temática e os existentes seguem um padrão, todos realizados dentro de laboratórios e com alunos de sexto anos adiante e ensino médio. Sendo assim podemos destacar a relevância de novos estudos científicos sobre C.C em Escolas do/no Campo contemplando o Currículo do Ensino Fundamental I, pois durante esta pesquisa do Estado da Arte não foi encontrado nenhum trabalho nesse campo científico.

Desta forma essa pesquisa se mostra relevante, tanto para conhecimento científico como para a futura dissertação de mestrado da pesquisadora, que pretende analisar como as práticas pedagógicas realizadas no C.C de uma Escola do/no Campo, proporcionou uma reestruturação curricular a partir da diversidade do territorial escolar.

\section{REFERÊNCIAS}

ARROYO, M. G. Currículo, território em disputa. Rio de Janeiro: Vozes, 2013.

BRASIL. Lei LDB n. 9.394/96. 1996. Disponível em: <http://www2.camara.leg.br/legin/fed/lei/1996/lei-9394-20-dezembro-1996-362578publicacaooriginal-1-pl.html>. Acesso em: 20 ago. 2020.

BRASIL. Diretrizes Curriculares Nacionais para o Ensino Fundamental. 2013. Disponível em: <http://portal.mec.gov.br/docman/julho-2013-pdf/13677-diretrizeseducacao-basica-2013-pdf/file>. Acesso em: 10 jul. 2020.

CHASSOT, A. Alfabetização científica: uma possibilidade para a inclusão social. Revista Brasileira de Educação, n. ${ }^{\circ}$ 22, p. 89-100, 2003. Disponível em: <http://www.scielo.br/pdf/rbedu/n22/n22a09.pdf>. Acesso em: 22 jun. 2020.

CLUBE DE CIÊNCIA DO CAMPO. Programa de formação de professores. 2020. Disponível em: <https://www.ufrgs.br/clubedeciencias/>. Acesso em: 22 out. 2020. 
FLICK, U. Uma introdução à pesquisa qualitativa. 2. ed. Porto Alegre: Bookman, 2004.

FREIRE, P. Pedagogia do oprimido. 57. ed. Rio de Janeiro: Paz e Terra, 2014.

GIL, A. C. Como elaborar projetos de pesquisa. 2. ed. São Paulo: Editora Atlas, 2000 .

GOMES, C. M. B. Aspectos Psíquicos e Políticos do Ensino no Clube de Ciências. Revista do PROCIRS. Porto Alegre: FDRH, v. 1, n. 1, 1988.

MANCUSO, R. Clubes de Ciências: Criação, Funcionamento, Dinamização. Porto Alegre: CECIRS, 1996.

MOLINA, M. C.; JESUS, S. M. S. A. de. Por uma Educação do Campo. Brasília: Articulação Nacional, 2004.

ROSA, S. S. DA; ROBAINA, J. V. L. O Ensino de Ciências nas Escolas do Campo a partir da análise da produção acadêmica. Revista Insignare Scientia - RIS, v. 3, n. 2, p. 156-175, mai/ago, 2020.

SILVA, E. L.; MENEZES, E. M. Metodologia da pesquisa e elaboração de dissertação. Florianópolis: UFSC/PPGEP/LED, 2000. 